\title{
La c/a/r/tografía en el aula como instrumento de desarrollo creativo, visual y de pensamiento complejo a través de las artes
}

\section{Resumen}

El presente artículo revisa la cartografía tradicional, crítica, artística, el mapeo cultural y el comunitario, en su relación con la 'cartografía social pedagógica y artística' en auge desde la educación artística en los últimos tiempos. Se propone la necesaria diferenciación de la 'cartografía social pedagógica y artística' bajo el término c/a/r/ tografía y se justifica la necesidad de una mayor definición a partir de los postulados de la perspectiva de la a/r/tografía. El objetivo es comprobar el funcionamiento y rasgos característicos de la c/a/r/tografía como metodología visual de investigación artística y docencia. Mediante Investigación Basada en las Artes se recogen datos, en un estudio de 13 casos desarrollados en la Universitat de València, que son analizados con métodos cualitativos. Los resultados categorizan cómo, en las c/a/r/tografías, se visualizan las conexiones, cómo se superpone la información en el proceso, cómo es el proceso creativo y de participación, y cómo se distribuyen sus creadores en el espacio. Finalmente, se ofrece una contribución teórica sobre las características generales, técnicas y creativas de las c/a/r/tografías. La c/a/r/tografía es al mismo tiempo una obra de arte, mapa y representación; un contenido educativo en un momento de enseñanza o taller; una escultura social o evento relacional; una reflexión, una historia, un diálogo y una indagación. Como instrumento de investigación facilita el análisis de datos, la exposición de resultados y la discusión compartida. Las principales conclusiones tienen que ver con su capacidad para alfabetizar visualmente y generar pensamiento complejo compartido.

\section{Ricard Ramon}

Doctor en Arte y Filosofía.

Universitat de València, Valencia, España.

Correo electrónico: ricard.ramon@uv.es ๑ orcid.org/0000-0003-1009-2589

\section{Google Scholar}

\section{Amparo Alonso-Sanz} Doctora en Didácticas Específicas. Universitat de València, Valencia, España.

Correo electrónico:

m.amparo.alonso@uv.es 구 orcid.org/0000-0002-1965-8203

\section{Google Scholar}

\section{Recibido: marzo 12 de 2021} Aprobado: agosto 18 de 2021

\section{Palabras clave:}

cartografía, creatividad, estudio de caso, educación artística. 


\section{$\mathrm{C} / \mathrm{a} / \mathrm{r} / \mathrm{tog}$ raphy in the classroom as an instrument of creative, visual and complex thought development through the arts}

\begin{abstract}
This article reviews traditional, critical, artistic cartography, cultural and community mapping in their relationship with the 'pedagogical and artistic social cartography' that has been on the rise in artistic education in recent times. The necessary differentiation of the 'pedagogical and artistic social cartography' is proposed under the term $\mathrm{c} / \mathrm{a} / \mathrm{r} /$ tography and the need for a greater definition based on the postulates of the $\mathrm{c} / \mathrm{a} / \mathrm{r} /$ tography perspective is justified. The objective is to verify the operation and the characteristic features of $\mathrm{c} / \mathrm{a} / \mathrm{r} / \mathrm{tography}$ as a visual methodology for artistic research and teaching. Through Research Based on the Arts data are collected in a study of 13 cases developed at Universidad de Valencia which are analyzed with qualitative methods. The results categorize how $\mathrm{c} / \mathrm{a} / \mathrm{r} /$ tographies connections are visualized. how information is superimposed in the process, what the creative and participatory process is like, and how its creators are distributed in space. Finally, a theoretical contribution is offered on the general, technical and creative characteristics of $\mathrm{c} / \mathrm{a} / \mathrm{r} / \mathrm{tog}$ raphies. The $\mathrm{c} / \mathrm{a} / \mathrm{r} / \mathrm{tog}$ raphy is at the same time a work of art, a map and a representation, an educational content in a moment of teaching or in a workshop, a social sculpture or relational event, a reflection, a story, a dialogue and an inquiry. As a research instrument, it facilitates data analysis, results presentation and shared discussion. The main conclusions have to do with their ability to visually literate and generate and shared complex thinking.
\end{abstract}

Key words:

cartography, creativity, case study, arts education. 


\section{Introducción}

El presente artículo plantea el análisis de diferentes experiencias desarrolladas en el aula con alumnado universitario. Partimos de los modelos construidos del a/r/tography (Irwin y De Cosson, 2004; Irwin et al., 2006; Springgay et al., 2008; Irwin et al., 2018), una perspectiva investigadora que consiste en mantener una triple relación entre la acción artística, la práctica docente y la investigación de manera que todas estas facetas se construyen de forma conjunta e interrelacionada. Esto nos sirve como base para trazar un camino que nos lleva a explorar el uso de la cartografía en el aula como un medio visual y creativo sobre el que trabajar desde diferentes ámbitos pedagógicos hasta evolucionar en las acciones de creación de c/a/r/tografías. Estas llevan un paso más allá la idea inicial de la cartografía hacia un escenario de trabajo exclusivamente de diseño visual y artístico.

El objetivo de investigación se articula en torno a la indagación de la c/a/r/ tografía, a partir de su desarrollo en diferentes experiencias de aula. Consiste en comprobar el funcionamiento, la dinámica y los rasgos definitorios de la c/a/r/tografía como metodología visual de investigación artística y docencia.

\section{De la cartografía a la c/a/r/tografía}

La cartografía como ciencia que estudia los mapas y las cartas geográficas y como técnica que deriva en la forma en que se realizan, nos interesa especialmente. A través de la cartografía se han analizado medidas y datos de regiones de la Tierra, para representarlas gráficamente con diferentes dimensiones lineales o escalas en forma de documentos territoriales. A la cartografía académica se le ha supuesto una objetividad que la cartografía social (Barragán-León, 2019) y crítica se ha encargado de desenmascarar. Crampton y Krygier (2006) invitan a examinar las relaciones de poder implícitas en la construcción histórica, 
nos hacen reconocer los grados de subjetividad intencional del conocimiento geográfico. Desde ahí partimos nosotros, desde el valor de lo subjetivo en las representaciones. La cartografía entendida como forma de exponer resultados reflexivos relacionados con lo cultural, lo histórico y lo político del territorio a través de la representación bidimensional.

La cartografía también ha sido una forma de mostrar resultados perceptivos, emocionales y psicológicos en relación con el territorio, el espacio urbano o el espacio íntimo. Así lo constatan las psicogeografías, resultado de una experiencia flâneuse en la metrópoli, o bien de la deambulación como flâneur (Alonso-Sanz, 2020a). Desde los años 60 del siglo XX subvirtiendo la cartografía tradicional (Pinder, 1996) se generaron cartografías de gran interés artístico a partir de las desviaciones o derivas urbanas situacionistas, actividad basada en los paseos, que responden al espacio-ciudad y actúan como una estrategia subversiva para resistir los sistemas de movimiento dominantes (Pérez y Libersat, 2016). A pesar de las grandes aportaciones hechas por movimientos como el Avant-garde, los surrealistas, situacionistas, algunos artistas conceptuales y postconceptuales, la cultura popular, los mapas bélicos pictóricos... Bassett (2004) reclama la necesidad de representar, con nuevas formas, estilos o estrategias, los estados de conciencia y sensación. Esto nos provoca, en un sentido pedagógico, a explorar estas posibilidades artísticas desde la enseñanza y con la comunidad educativa.

El mapeo cultural (Rossetto, 2015) y comunitario (Sinker et al., 2013; Chiesi y Costa, 2015; Lenz, 2016; Yilmaz, 2016; Bertling, 2017) se presenta como el método perfecto de recolección de datos cuando se trata de recabar información derivada de la participación de un colectivo que debe reflexionar sobre su territorio. Según Chiesi y Costa (2015), el mapeo cultural es una herramienta para enumerar las instancias tangibles e intangibles del capital cultural de un lugar. 
Los mapas, con sus distintas imágenes, escalas y símbolos se convierten en obras de extremo valor estético. "Important branches of geography and art are rooted in common ground" (Rees, 1980, p. 60). Son históricamente herramientas cartográficas las técnicas de grabado, de dibujo y pintura. Además, hay que considerar que cualquier sistema de reproducción de estas representaciones también imprime con su tecnología una determinada estética, un acabado que variará según se emplee un tipo de imprentas, tintas, toners...

En la formación del profesorado encontramos múltiples ejemplos de experiencias de cartografía social educativa. Estas investigaciones pedagógicas desarrollan articulaciones entre territorio, construcción de subjetividades y búsqueda de transformaciones socioeducativas, a partir de la creación o utilización de símbolos ubicados en mapas, poniendo énfasis en el contexto y la situacionalidad (Giraldo y Báquiro, 2014; Baldivieso et al., 2020).

De manera casi simultánea a la cartografía social pedagógica, en la que se intenta trasladar ciertos aspectos de la cartografía social al campo educativo, en cuanto vía para transformar la educación (Barragán, 2016), ha nacido la cartografía social artística, la cual pretende abrirse camino en el ámbito de los procesos de indagación en el arte. (Bolaños-Motta y Pérez-Rodríguez, 2019, p. 55)

Recientemente, la cartografía, como enfoque epistemológico y metodológico, ha sido utilizada en entornos educativos para explorar las transiciones de futuros docentes en sus experiencias de aprendizaje (Rousell y Lasczik, 2014; MacayaRuiz, 2017; Hernández et al., 2018), así como de actuales docentes de infantil y primaria (Gorospe et al., 2017; Barragán y Aberasturi-Apraiz, 2019; AberasturiApraiz et al., 2020a; Gallego-Lema et al., 2020) o profesorado de secundaria (Hernández, 2018; Sancho-Gil et al., 2018; Carrasco-Segovia y HernándezHernández, 2020). También se ha empleado para el reconocimiento de la autoridad femenina en los procesos de aprendizaje en una escuela pública para mujeres o para la configuración de la identidad docente en el caso de estudiantes de pedagogía LGBTI+ (Montenegro, 2019) o con jóvenes para 
evidenciar tanto problemáticas sociales como procesos de aprendizajes de manera colectiva (Carrasco-Segovia et al., 2019). Es decir, siempre vinculada a relaciones pedagógicas entre jóvenes y adultos. La cartografía se ha constatado como instrumento de indagación colectiva, imágenes que permiten procesos de pensar (Aberasturi-Apraiz et al., 2020b) como nuevas estrategias de investigación y de representación de lo narrado mediante imágenes (Gorospe et al., 2017), "como un dispositivo rizomático que relaciona ideas y accede a los datos desde diferentes puntos" (Gallego-Lema et al., 2020, p. 167).

Por un lado, en las aportaciones de estas investigaciones que tanto valoramos, encontramos problemática, la confusión que puede existir entre una forma de representación puramente cartográfica, vinculada a un espacio físico existente desde el que se parte; y la representación artística, vinculada a la expresión metafórica de conceptos, estados mentales, emocionales o recuerdos de vivencias. Macaya-Ruiz alertaba en 2017 que la enorme popularización del término cartografía y su abuso se relaciona con la necesidad de explorar nuevas formas de representar el conocimiento y visualizar conexiones, no solo entre lugares, sino también entre conceptos e ideas. Por eso nos planteamos la conveniencia, no solo de diferenciar las cartografías tradicionales de lo que podemos considerar cartografías sociales artísticas o visuales, sino insistir además en el nombre c/a/r/tografías (Rousell y Lasczik, 2014; Lasczik e Irwin, 2017) para otorgarles el valor estético y sentido investigador en contextos educativos que se viene defendiendo desde la educación artística en los últimos años.

El término utilizado para este tipo de acciones, c/a/r/tografía, aunque se base en los postulados de las perspectivas del a/r/tography, hace referencia a la cartografía, pero insistiendo en el término arte (Ramon, 2021) en lugar de carta, que remite a mapa y grafía que hace referencia al dibujo de esos mapas. En este caso, los mapas, aunque de alguna manera siguen existiendo, dan prioridad a lo artístico, lo exclusivamente visual para construir a través 
de un pensamiento basado en las imágenes artísticas y en el diseño. Las c/a/r/ tografías sirven para trabajar cualquier tema o realidad del mundo, igual que las cartografías, pero desde una mirada y una perspectiva exclusivamente visual, artística y simbólica.

Hasta el Renacimiento no había terminología para distinguir claramente entre mapas y pinturas (Ree, 1980), y ahora convendría distinguir entre cartografías y c/a/r/tografías. ¿Pero cómo se definen exactamente las c/a/r/tografías? Rousell y Lasczik (2014) acuñan el término como "visual mapping as an approach to performing (rather than representing) the interrelationships between art, teaching and research" (p. 69). A nuestro parecer, la c/a/r/tografía toma la letra c (cartography) de la asociación a la cartografía, pero especialmente a la cartografía social pedagógica y artística y al mapeo comunitario; la letra a (artist) de las prácticas artísticas, especialmente las contemporáneas; la letra $r$ (research) refuerza el sentido de instrumento dentro de una metodología de investigación a/r/tográfica que enfatiza lo colaborativo; que es aplicado por investigadores-docentes en un contexto educativo, latente en la letra $t$ (teachers); y finalmente representado gráficamente (grafía).

La función principal de la c/a/r/tografía es facilitar la investigación, creación y enseñanza de forma gráfica y simultánea. Se debe insistir en trabajar estas cuestiones de forma integrada y conjunta. Para ello es imprescindible entrecruzar el rol investigador, artístico y docente de quienes las elaboran. Quienes participan deben asumir de forma consciente estos roles con independencia de que hasta el momento no sean a nivel profesional o experto, investigadores, artistas o profesores. Con independencia de la edad del alumnado, este puede desarrollar interesantes pesquisas por ejemplo en el aprendizaje basado en proyectos, puede asumir las labores de enseñantes de sus iguales en el trabajo cooperativo, y puede desempeñar grandes dotes creativas en el diseño artístico de las representaciones. 
Conocemos por Rousell y Lasczik (2014) que el resultado de la c/a/r/tografía es "an artwork, a curriculum, a teaching moment, a workshop, a social sculpture, a relational event, a painting, a map, a reflection, a story, a dialogue, and an inquiry" (p. 71); todo ello a la vez y de forma inclusiva. Sabemos gracias a Bolaños-Motta y Pérez-Rodríguez (2019) que la c/a/r/tografía "habrá de ir acompañada de una pregunta dirigida al interior del artista investigador, (...) plasmada sobre el papel en el cual se va a hacer la cartografía, o (...) expresada de forma oral por quien preside el acto investigativo" (p. 55). Sin embargo, aun cuando constatamos que se dan todos estos condicionantes, nos falta por definir qué pautas, ejemplos u orientaciones deben recibir quienes crean c/a/r/ tografías para desempeñarse en su elaboración de forma creativa.

Por otro lado, observamos en los antecedentes consultados que los resultados de las investigaciones versan en su mayoría sobre problemas pedagógicos. Solo algunos investigadores citan el uso de referentes artísticos en la práctica de las cartografías comunitarias (Macaya-Ruiz, 2017; Alonso-Sanz, 2020a) por sus oportunidades estilísticas, técnicas, matéricas, compositivas... En general, hay una ausencia de reflexión sobre las oportunidades estéticas del propio instrumento. Pero:

(...) si la visualización de la complejidad pasa por el uso de redes, tanto conceptuales como visuales, deberemos profundizar en el mecanismo y principios que las regulan para poder generar una decodificación de las mismas y una taxonomía capaz de visualizarlas y comprenderlas. (Pizarro, 2017, p. 90)

Este análisis es necesario desde la educación artística, porque a menudo se c/a/r/tografía con personas inexpertas en las disciplinas artísticas, que pueden carecer de una alfabetización visual, dominio técnico o habilidades necesarias en el proceso expresivo y creativo. Este análisis es preciso si queremos formar a futuros docentes para su traslado a las aulas de infantil, primaria y secundaria. 


\section{Método}

El método empleado para el desarrollo de esta investigación se centra especialmente en la Investigación Basada en las Artes (Sullivan, 2005; McNiff, 2013; Leavy, 2018) desde la perspectiva del a/r/tography (Irwin y De Cosson, 2004; Irwin et al., 2006; Springgay et al., 2008; Irwin et al., 2018; Marín-Viadel y Roldán, 2019) para la recogida de datos a partir de experiencias en las aulas.

Estas experiencias se plantean como un estudio de casos múltiples (López, 2013) por ser evidencias exploratorias de un método c/a/r/tográfico emergente en educación artística que precisaba ser experimentado con diferentes audiencias, en diferentes contextos educativos y mediante técnicas variadas. Los casos se han seleccionado por su accesibilidad, experiencias realizadas por los investigadores-docentes, obteniendo información, documentos e imágenes con y de quienes participaban. Aun cuando los materiales que se analizan son de elaboración del alumnado, en todo momento este es conocedor de que se toman registros con fines investigadores, respetando su anonimato y reconociendo su autoría. Esto nos permite tener mayores elementos para explicar e interpretar la realidad que estudiamos. Se trata de un estudio longitudinal a lo largo de casi cuatro años, desde 2018 hasta 2021.

Posteriormente y dentro de un paradigma cualitativo (Richards, 2006) se analiza el relato de estas experiencias y las propias imágenes en busca de la categorización de rasgos comunes definitorios de la c/a/r/tografía. Según Richards (2006), los métodos visuales posmodernos de investigación ofrecen estas posibilidades de análisis porque cada imagen cuenta una historia y abre oportunidades para nuevas visualizaciones en la investigación cualitativa; las representaciones visuales son textos legítimos que comunican significado; la semiótica visual asume que los símbolos, dibujos y las imágenes representan la realidad; y la teoría de la codificación dual conecta el sistema simbólico 
de cognición con el lenguaje escrito y las imágenes, argumentando que este vínculo fomenta mayores opciones de comunicación.

Las experiencias c/a/r/tográficas objeto de estudio se desarrollan con 414 estudiantes de la Universitat de València. Entre los colectivos participan estudiantes del Grado de Maestro/a de Educación Primaria (GMEP), del Grado de Maestro/a de Educación Infantil (GMEI), del Máster de formación del profesorado de Educación Secundaria (MAES) y del Máster de Investigación en Didácticas Específicas (MUIDE). Cada estudiante se enfrenta al reto de c/a/r/tografiar desde la asunción del rol docente, artístico e investigador. Junto a nosotros que somos profesores, artistas e investigadores que les guiamos, adquirirán a través de la práctica la experiencia necesaria para su desarrollo. Se trata de una preparación del perfil que al egresar tendrán como educadores artísticos con necesidad de investigar.

En cada uno de los 13 casos estudiados las preguntas que motivan la acción c/a/r/tográfica son diferentes y se especifican en el siguiente apartado.

Para la recogida de datos se emplea el registro fotográfico de las sesiones de aula, los diarios de campo para conservar las reflexiones conjuntas que emergen en el aula, los comentarios del alumnado en los portafolios empleados en su evaluación, así como las propias creaciones c/a/r/tográficas. Todos estos datos sustentan el análisis y los resultados de este estudio.

\section{Resultados. Estudio de casos vinculados a las c/a/r/tografías.}

Se enumeran a continuación 13 experiencias en el desarrollo de c/a/r/tografías desde 2018 hasta 2021, y documentando los procedimientos utilizados con imágenes. Posteriormente se hace un análisis cruzado de estos casos que nos permite comprender mejor los procesos de desarrollo de las c/a/r/tografías. 
MAES. Enero de 2018.

Un grupo de 7 estudiantes decidió indagar sobre los temas de investigación que les atraían a partir de un diálogo visual para consensuar un interés común. Este proceso fue caótico en sus inicios, desconcertante por la cantidad de temas que se abrían frente sí. Sin embargo, la confrontación de imágenes los llevó a confluir en un aspecto compartido. Como resultado, acordaron estudiar los aprendizajes que cada cual obtenía a diario en diferentes medios de transporte hasta Ilegar a la Universidad. Representaron en una c/a/r/tografía sobre un corcho del pasillo sus reflexiones a través de un plano de la ciudad de Valencia.

\section{GMEI. Octubre de 2018.}

Un grupo de 50 estudiantes, aproximadamente, se enfrentaron al reto de concebir los patios de las escuelas como lugares pedagógicos para la transmisión de valores coeducativos e inclusivos. Divididos en equipos de 10 personas máximo, visitaron una escuela y conocieron sus zonas de recreo. En el aula reflexionaron a través de cartografías tridimensionales sobre los cambios que podían imaginar y las necesidades que los justificaban. Para discutir las posibilidades emplearon pastas de modelar y juguetes variados, configurando transformaciones poco tradicionales.

\section{MAES. 15 octubre de 2018.}

En esta acción se trabajó simultáneamente con dos clases sobre un papel que cubría la totalidad del aula, convirtiendo el suelo en la superficie de trabajo y los cuerpos en agentes de acción. Se trataba de la primera sesión del curso, con 80 estudiantes aproximadamente que procedían de estudios de Grado muy diversos. El ejercicio c/a/r/tográfico permitió reflexionar sobre los propios 
intereses pedagógicos que los Ilevaban a estudiar el Máster de formación del profesorado de secundaria, así como conocer a sus iguales en busca de conexiones y espacios de entendimiento compartido.

\section{MAES. 29 octubre de 2018.}

El alumnado del MAES se enfrentaba al reto de la innovación docente sin conocer cuáles eran las principales líneas de investigación que se vienen desarrollando en educación artística en las últimas décadas. La docente los invitó a reflexionar con la creación de c/a/r/tografías sobre temas como: el patrimonio, la cultura visual, el espacio en el aprendizaje, el perfil del docente de educación artística... A través de una dinámica de talleres rotativos, dos clases de 40 estudiantes cada una dividida en equipos de entre 8 y 10 personas, se enfrentó a estos interrogantes propuestos a priori por la docente para revisar qué entendían sobre estos conceptos. Situados alrededor del papel comenzaban titulando el tema que les interrogaba en esa c/a/r/tografía. Rotaban y en otra diferente dibujaban y grafiaban sus ideas al respecto. Con cada rotación se enfrentaban a representaciones previas hechas por otro/s equipo/s en un tema diferente, y añadían o complementaban un discurso que solo conocían en su expresión visual.

\section{MAES. Noviembre de 2018.}

El mismo alumnado de las dos experiencias anteriores, conocedor ya del uso de las c/a/r/tografías, se enfrentó a emplearlas en una investigación conjunta. El problema al que se los enfrentó fue el conocimiento del entorno en el que estudiaban, el barrio de Monteolivete de Valencia, un lugar de contrastes en tradición y contemporaneidad donde se encuentra la famosa Ciudad de las Artes y las Ciencias. La recogida de datos se realizó mediante la técnica de investigación de la deriva. Durante la exploración se fue registrando la 
información por equipos según las siguientes técnicas: grabación de sonidos, transcripción de conversaciones que escuchaban, toma de fotografías y realización de dibujos. La c/a/r/tografía les permitió exponer los resultados a la vez que discutirlos e interpretarlos grupalmente. Se distribuyeron por el suelo los dibujos y fotografías, sin limitación de formato, y decidieron trazar con líneas rojas las avenidas principales del barrio y abatir sobre ellas sus creaciones, en los lugares donde habían sido registrados.

\section{GMEl. Enero de 2019.}

La tutorización de las prácticas del Grado de maestro/a cuenta con algunas sesiones grupales. Con un equipo de 6 estudiantes, aprovechamos la ocasión para poner en común los descubrimientos que cada alumna había tenido en sus escuelas en búsqueda de experiencias similares o complementarias. A partir de anotaciones en sus diarios de campo, objetos, dibujos, regalos de sus escolares... crearon una c/a/r/tografía. El esquema que estructuró la organización de sus reflexiones fue un plano en planta de una escuela ficticia.

\section{MAES. Noviembre de 2019.}

Casi 80 estudiantes del MAES participaron en la elaboración de una c/a/r/ tografía que mapeó los espacios de violencia machista de la ciudad de Valencia (Alonso-Sanz, 2020b). La amplitud del problema obligó a plantear la representación fragmentada en tres paramentos. Se dibujó un plano general de los barrios de la ciudad, otro para la zona norte de Valencia y otro para la zona sur. Se usó una leyenda de acciones de violencia, mediante códigos de colores, con la que se invitó a quienes visitaban el entorno a responder pintando en el muro donde habían sufrido violencia en el espacio público. La c/a/r/tografía se tornó abierta a la transformación viva. 


\section{MAES y GMEP. Noviembre de 2019.}

La práctica propuesta en este caso tenía una serie de fases de desarrollo que iban del trabajo individual al colectivo, volviendo de nuevo al individual y finalizando en la creación de una c/a/r/tografía colectiva (Figura 1). Participaron 80 estudiantes del MAES y 45 del GMEP. La pretensión pedagógica era aprender a crear imágenes con capacidad simbólica, a partir de elementos visuales y del diseño, con las que analizar y reflexionar sobre el mundo, ofreciendo alternativas a este a partir de problemáticas sociales y educativas. Se percibe cómo van evolucionando hacia la ordenación visual de ideas y conceptos. Establecen una estructura de relaciones de carácter totalmente creativo y exclusivamente visual.

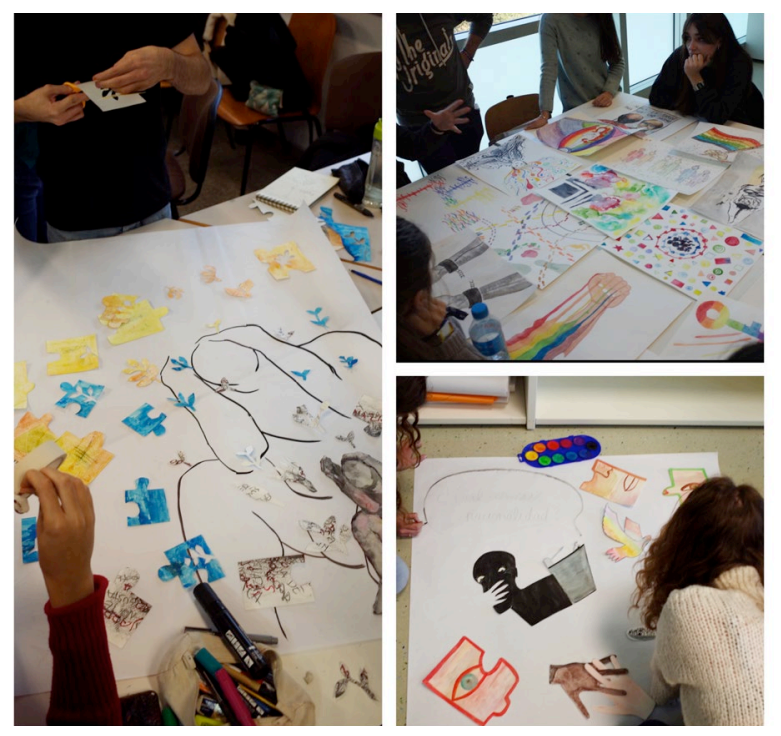

Figura 1. Grupos de alumnos trabajando en los procesos creativos y de pensamiento visual en la elaboración de las c/a/r/tografías. 


\section{MUIDE. Febrero de 2020.}

En esta propuesta se trabajó, dado el carácter de formación en investigación del alumnado (6 estudiantes), en la utilización de las c/a/r/tografías como un medio de indagación sobre su propio perfil investigador que estaba en proceso de gestación. Las reflexiones que emergen a partir de este método permitieron visualizar y navegar por determinadas complejidades que surgen durante el proceso. Especialmente al poner en común los diferentes perfiles, y buscar esas relaciones, problemáticas y complejidades de forma conjunta. Esto permitió alcanzar un grado de madurez en el desarrollo de los pensamientos asociados al perfil investigador en gestación y consolidó su propia mirada, gracias al recurso del proceso visual y creativo ejercido en la acción.

\section{MAES. Diciembre de 2020.}

En este caso, un grupo de 40 estudiantes utilizó esta forma de creación visual como un medio para obtener y elaborar un tema de investigación. Se partía de una indagación sobre ellos utilizando una serie de imágenes simbólicas mediante los que vincular sus intereses a sus relatos biográficos y los temas de investigación que van emergiendo en el proceso creativo de la c/a/rtografía (Figura 2). Partimos de la propuesta triangular de Ana Mae Barbosa (Barbosa y Pereira da Cunha, 2012) para establecer un eje sobre el que el alumnado pudiera construir la relación en la búsqueda de los temas de investigación para su TFM (Trabajo de Final de Máster). A partir de las propuestas de desarrollo de una $\mathrm{c} / \mathrm{a} / \mathrm{r} /$ tografía, el alumnado pudo explorar las distintas opciones en función de lo que identificaron como sus intereses primordiales, enmarcados dentro del eje triangular sobre el que se mueve la educación artística, la práctica, la percepción y la contextualización en un espacio y entorno sociocultural e histórico. Les permitió abordar la búsqueda de un tema de investigación y ordenar sus ideas y conceptos de una manera más eficiente. 


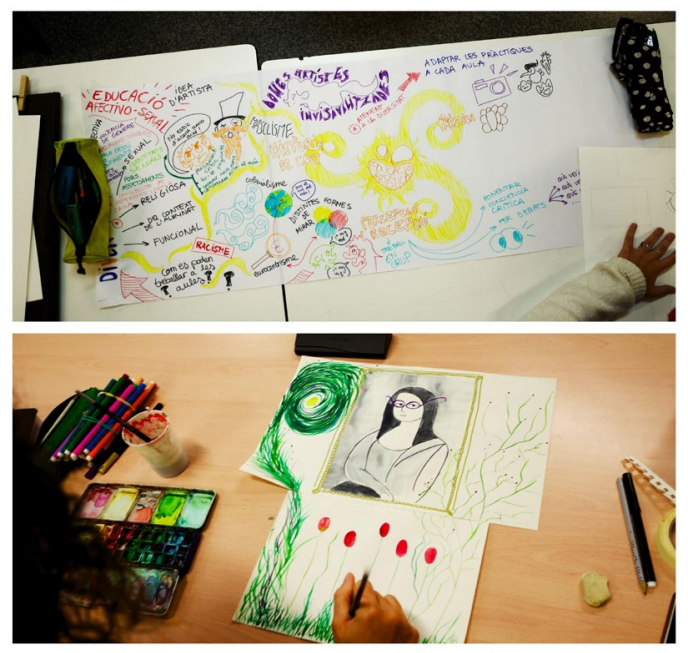

Figura 2. Alumnado trabajando en la búsqueda de su tema de investigación a partir de este método. Fuente: propia.

\section{GMEP. Enero de 2021.}

Uno de los estudiantes del GMEP, para la elaboración del portafolio con el que se evaluaría su aprendizaje durante el cuatrimestre, decide utilizar el recurso de la c/a/r/tografía. En ella logra situar trabajos y entregables, hobbies e intereses personales, lecturas recomendadas, referentes artísticos y teorías que interiorizó y con los que dialogó. Qué aprendizajes fueron significativos, le afectaron y transformaron quedando materializados en un muro del parque de Marxalenes en Valencia. Durante su elaboración necesitó incluir la ayuda de dos amigas con las que reflexionar visualmente de forma compartida aun tratándose de un trabajo individual. También interactuó con visitantes de los jardines y con un policía que decidió no obligar a retirarla hasta ser finalizada. 


\section{MUIDE. Febrero de 2021.}

Acción online a causa del Covid-19, lo que implica que 13 estudiantes trabajaban desde sus casas, por lo que se incluye esta y el concepto de hogar como un espacio sobre el que desarrollar nuestras prácticas educativas. El objetivo era desarrollar una c/a/r/tografía (Figura 3) para trabajar sobre las relaciones que se establecen en el entorno más próximo, y de esta forma analizar, desde una perspectiva pedagógica, la propia situación. Se trataba de ejercer y trasladar un pensamiento sobre las acciones cotidianas y sobre cómo se percibe el hogar propio, tanto desde un punto de vista físico como conceptual y experiencial, pero solamente a través de los medios visuales y de los procesos creativos.

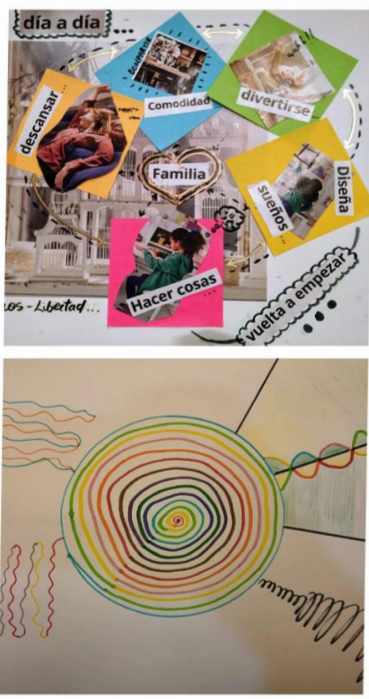

Figura 3. Algunos ejemplos de los procesos de trabajo visual realizados por el alumnado en una docencia a distancia. Fuente: propia. 


\section{Análisis de las 13 experiencias c/a/r/tográficas}

Hemos elaborado una tabla (Tabla 1) donde realizamos una síntesis de todas las experiencias analizadas como evidencias y las ponemos en relación con los factores de análisis para facilitar su comprensión de forma visual.

Tabla 1. Síntesis visual del análisis de experiencias cartográficas desarrolladas desde 2018 hasta 2021

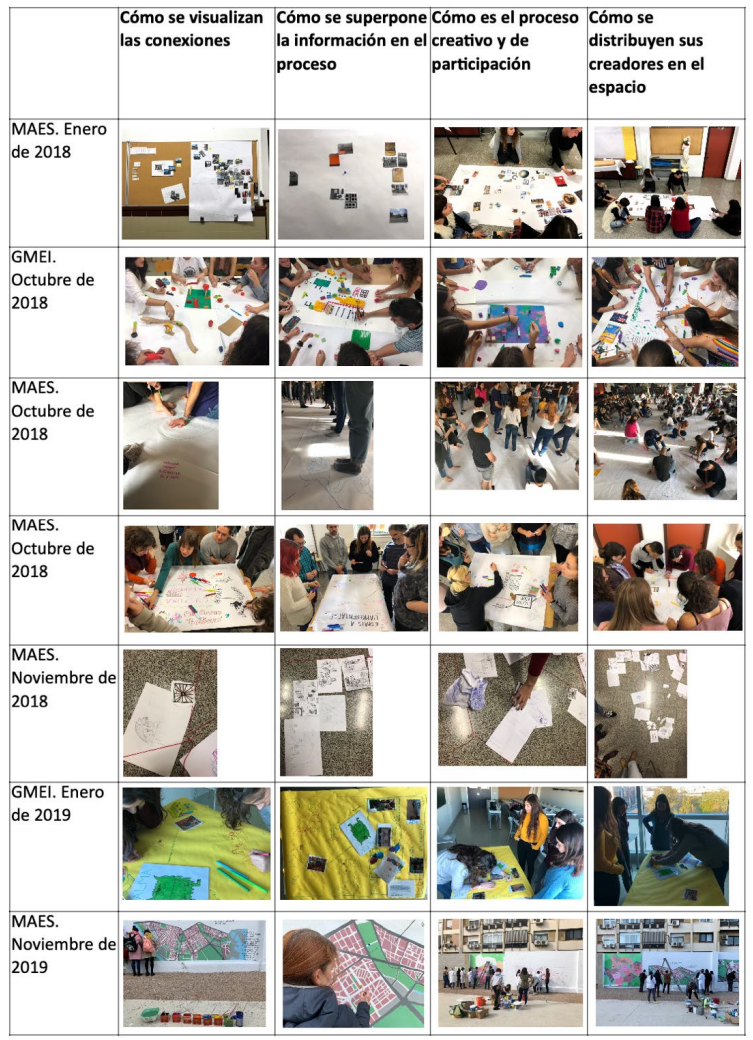




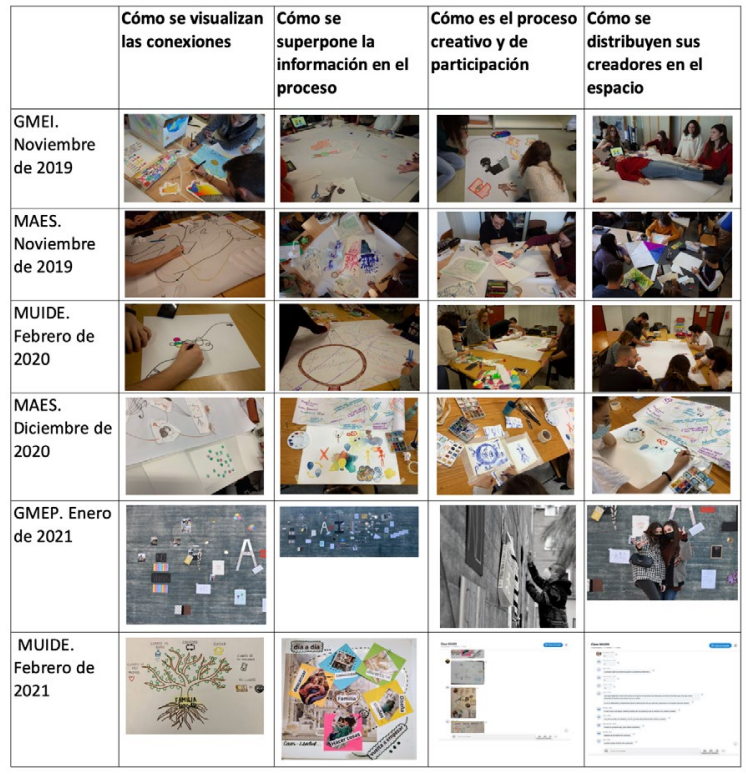

Fuente: propia.

Las tablas visuales de doble entrada exponen los resultados agrupados en filas de las experiencias creativas y pedagógicas de las c/a/r/tografías que hemos ido realizando en los últimos años. En las columnas se recoge información visual muy significativa que muestra de qué forma se desarrollan estos procesos conforme a cuatro categorías. A continuación, se exponen los principales hallazgos.

A. Cómo se construyen y visualizan las conexiones en las c/a/r/tografías. Un aspecto esencial en el diseño y resignificación constante de los elementos visuales que las constituyen, así como en la creación de conceptos y símbolos. Observamos que estas pueden materializarse de forma muy diversa: mediante 
chinchetas y cordeles o lanas; con cintas de carrocero que permiten escribir sobre ellas; a través de puentes, carreteras o caminos (trazados o con juguetes en maquetas); gracias a la interacción del propio cuerpo situado sobre el soporte; mediante líneas (continuas, discontinuas en zigzag) o grafismos de distintos grosores y espesores; gracias a una leyenda de colores u otras asociaciones cromáticas (en letras, fondo, siluetas); mediante frases escritas de forma continua (letras cogidas de la mano). Pero además se recurre frecuentemente a iconos como el árbol, el rizoma, el puzzle, el sistema planetario y otros esquemas que por su propia distribución facilitan la estructuración simbólica de conceptos en ramas, raíces, piezas, planetas... Sin embargo, la c/a/r/tografía es todo un proceso en constante evolución, no simplemente un resultado final. A diferencia de recursos como los mapas mentales, conceptuales u esquemas (que pueden ser parte o integrarse en una c/a/r/tografía) en los que solo importa la imagen última que comunica unos conceptos o ideas, en la c/a/r/tografía priman el componente poético, la función educativa, las interrelaciones, las reflexiones, las historias, los diálogos y la indagación.

B. Cómo se superpone la información en el proceso. En relación con cómo se van elaborando las diferentes capas de información que definen la c/a/r/ tografía, a través del proceso de creación, los recursos son de toda índole. Cuando se emplean materiales como dibujos o fotografías estas se solapan, se yuxtaponen, se transparentan (si el papel es translúcido como el vegetal) o incluso se recortan para formar una nueva composición en collage. En el caso de la pintura esta puede manchar, rellenar áreas o salpicarse, pero también hacer veladuras que es una forma de solapamiento del color. Cuando se emplean materiales tridimensionales como juguetes, objetos, pastas de modelar o el propio cuerpo las fuerzas que ejercen unos sobre otros producen una necesidad de desplazamiento o priorización, porque es más complejo compartir un mismo espacio en equilibrio. 
El texto juega un papel fundamental a la hora de crear varias capas de información (Huerta, 2020). Con la palabra se enfatiza, se complementa o se acota el significado de las iconografías que acompaña, es "la búsqueda de sentido en la combinación de textos e imágenes" (Marín-Viadel y Roldán, 2019). En ocasiones una fase previa desaparece de la c/a/r/tografía final, no deja rastro, queda como un esbozo perdido; otras veces los propios bocetos se incorporan para ser modificados.

C. Cómo es el proceso creativo y de participación, que en la mayoría de las acciones tiene un componente colaborativo y de cooperación en el trabajo conjunto.

Respecto al proceso de desarrollo creativo, es destacable que incluso en el caso del planteamiento del trabajo con ejercicios de tipo individual, los participantes han necesitado en todo momento de la interacción y colaboración de los demás para su construcción. Por ejemplo, observando con el resto, sus trabajos individuales, mientras se desarrollaban o posteriormente a su desarrollo, para reforzar y ampliar su mirada y su capacidad de comprensión. Este es un aspecto que permite de forma especial el trabajo con medios visuales, propiciando el intercambio permanente de conocimiento entre personas a través de las imágenes.

El juego, lo inesperado, el azar o la deriva también forman parte del proceso creativo porque es más sencillo dejarse llevar cuando la acción está acompañada de emociones en las discusiones, enfados, risas o bromas.

El contagio es otro factor fundamental, en la observación del modo de hacer, en la identificación de simbologías, metáforas, figuras retóricas y técnicas empleadas por otras personas o equipos... se produce una mímesis y reinterpretación que enriquece los resultados c/a/r/tográficos. Es junto con el 
conocimiento de referentes artísticos una de las mejores estrategias de fomento de la creatividad.

En el caso del desarrollo de c/a/r/tografías directamente grupales, el reparto de roles se va ejerciendo de una forma muy orgánica, tal y como hemos constatado en su desarrollo, donde prima más la acción que la discusión. Los participantes van aportando directamente, añadiendo o modificando visualmente al desarrollo conjunto del trabajo y permitiendo una discusión de tipo visual, un proceso vivo que se va tejiendo de forma compleja y autoorganizada. Un proceso de creatividad simbólica, colectiva y estética que se despliega en la experiencia, en términos deweyanos (Dewey, 2008).

En el formato online de sesión síncrona en el que se han compartido c/a/r/ tografías se reduce la forma orgánica de comunicación en favor de una sucesión de intervenciones y respuestas, de intercambio de ida y vuelta, de exposición y réplica, un chat visual y de texto que ralentiza el proceso.

D. Cómo se distribuyen sus creadores en el espacio. La forma de organización de las personas que participan en su creación es un aspecto muy importante, dado que condiciona el proceso y el resultado final. En el sentido que conforma trabajos que se visualizan y construyen desde diferentes perspectivas y ofrecen una respuesta visual encaminada al desarrollo de un tipo de pensamiento complejo, no lineal y multidimensional, desde el discurso visual.

La interacción de múltiples personas sobre un mismo soporte o formato obliga a distribuirse alrededor de este, normalmente rodeándolo, o bien cuando es posible incluso invita a situarse sobre el mismo, pisarlo y ocuparlo corporalmente, en estos momentos el cuerpo deviene parte de la c/a/r/tografía, símbolo y elemento constructivo. A diferencia de las cartografías clásicas que responden a un tipo de pensamiento más racionalizador y occidental, 
orientadas al norte, las c/a/r/tografías se organizan desde múltiples sentidos y direcciones lo que enriquece el conjunto de interrelaciones y significados.

El formato o superficie de trabajo en ocasiones resulta limitado y limitante, entonces se incorporan estrategias como el desplegado de papeles ( $p o p$ up), la adhesión colindante de otros soportes, la intervención fuera de encuadre o papel, en la mesa, suelo o pared.

Cuando la cartografía es elaborada por un equipo muy numeroso, aparecen reagrupaciones internas que hacen más factible el avance en tareas independientes. La comunicación entre esos subequipos se torna fundamental para llegar a consensos en la puesta en común de esas tareas.

En todo proceso artístico de creación de conocimientos compartidos, la experiencia estética juega un papel fundamental, y por lo tanto es necesario también revisar el resultado estético conjunto de las c/a/r/tografías, dado que este valor es esencial y está intrínsecamente unido al proceso. Para ser analizadas, debatidas y discutidas, no solamente por el grupo de personas que las han creado, sino también por el resto, las c/a/r/tografías se exponen en paramentos verticales, en espacios visibles, en el suelo de grandes áreas de circulación, incluso en ocasiones se exhiben en espacios públicos, permitiendo que el conocimiento generado traspase los límites del aula.

\section{La elaboración de la c/a/r/tografía y la alfabetización visual}

Con la puesta en común de todos los ejercicios planteados, se pone en valor la potencialidad alfabetizadora en el ámbito de la creación de pensamiento a través de medios visuales; al comprender el discurso visual y artístico que otros construyen y el suyo propio, con lo que el proceso de alfabetización visual se refuerza doblemente. Las c/a/r/tografías suponen un medio ideal para trabajar 
estrategias de alfabetización visual y establecer a partir de ellas, la base de la construcción de un tipo de conocimiento más creativo.

Se construyen a partir de una experiencia que se desarrolla especialmente en el trabajo colaborativo, ejercitada en el aula en diferentes variantes. Una forma de alfabetización visual que utiliza el camino recorrido por las cartografías para profundizar un poco más en esa dimensión que el diseño, exclusivamente visual y artístico, nos ofrece para comprender algunas dimensiones del mundo y permitir un enriquecimiento en la comprensión entendida como totalidad. Y que utiliza el camino recorrido por las a/r/tografías para explotar las oportunidades que ofrece el combinar simultáneamente los roles artísticos, investigadores y docentes tanto por parte del profesorado como del alumnado.

Este método de trabajo permite profundizar en la vertiente creativa al tiempo que se consolida como un modelo para el desarrollo de una alfabetización visual compleja y avanzada. Está vinculada al desarrollo simbólico, al planteamiento de conceptos y a la construcción de ideas, de nuevos mundos posibles (Goodman, 1990, 1995), a partir de medios artísticos y desde una vía cognitiva (Efland, 2004), que entiende el arte como un modo avanzado de creación de conocimientos.

\section{La elaboración de la c/a/r/tografía y el pensamiento complejo}

Analizadas las prácticas c/a/r/tográficas desde 2018 hasta 2021, hemos podido observar que la implicación del alumnado conlleva necesariamente la búsqueda de respuestas a la pregunta que motiva cada uno de estos ejercicios, desempeñando habilidades investigadoras. Para contestarla se esfuerzan en explicar a sus pares sus posicionamientos en un diálogo constante que los obliga a ejercer el rol docente y desarrollar funciones didácticas. Este diálogo, 
siendo visual y estético, exige una puesta en práctica de competencias artísticas y del diseño en los procesos perceptivos y creativos.

Trabajar en la alfabetización visual, en y desde procesos creativos y artísticos, permite abordar cuestiones y nuevas preguntas, desde un posicionamiento integral y más complejo que en los modos de aprendizaje esencialmente estructurados. Llegar más allá, gracias precisamente a la radicalidad de la imagen que nos facilita estructurar y navegar por posicionamientos y narrativas simbólicas, que incluso desafían el pensamiento lógico matemático y llevan el conocimiento humano hacia una dirección diferente y complementaria a los otros modos de entendimiento y aprendizaje del mundo.

Un proyecto a/r/tográfico usa metáforas y metonimias en lugar de hacer traducciones simples de los fenómenos que se investigan o de ceñirse a la mera literalidad de los datos empíricos. Prefiere la exégesis (interpretación) a la tesis (proposición o afirmación que se intenta demostrar con argumentos) y da prioridad a la diégesis (desarrollo narrativo) frente a la mímesis (copia o imitación). (Marín-Viadel y Roldán, 2019)

La elaboración de las c/a/r/tografías visuales permite el desarrollo de un análisis conjunto e integral entre el alumnado participante en el que las imágenes generadas constituyen una nueva oportunidad para mirar problemáticas a partir de relatos abiertos por el uso del diseño y los medios visuales. Estos ejercen, a partir de su poder simbólico, un tipo de representación de los problemas que permite repensarlos desde posicionamientos más imaginativos y atrevidos. De esta forma, "el cuestionamiento de la realidad como algo absoluto y preestablecido y la práctica interdisciplinar son necesarios para conseguir una mente dotada de estrategias innovadoras" (Muñiz de la Arena y Caeiro, 2019, p. 151).

La práctica de las c/a/r/tografías nos permite indagar en ese pensamiento complejo, multidimensional y no lineal, que es favorecido por el uso de un 
medio visual bajo una estrategia de trabajo creativa y artística. Un tipo de pensamiento que se conecta con los planteamientos de Edgar Morin (2004) y su definición del pensamiento complejo. Partiendo de la propia idea de sistema abierto, de la capacidad de autoorganización que se produce en el trabajo con las c/a/r/tografías, el papel de la creatividad en los mismos procesos de autoorganización del mundo afirmando que "la creatividad marca todas las evoluciones biológicas de manera aún más novedosa que la evolución histórica" (Morin, 2004, p. 80). Sitúa el papel ejercido por esta en un lugar primordial del desarrollo humano y, evidentemente, la idea del pensamiento complejo que se produce con este tipo de acciones a través de las prácticas visuales y artísticas.

Con las c/a/r/tografías partimos de la aparente contradicción entre el orden y el desorden o caos que se produce en su desarrollo: "el desorden y el orden, siendo enemigos uno del otro, cooperaban de alguna manera para organizar al universo" (Morin, 2004, p. 92). Ese desorden inicial que necesariamente se produce en las prácticas que hemos analizado es esencial en la construcción posterior de ese pensamiento complejo, que permite ir más allá de un orden establecido y ampliar sus límites en nuestras prácticas educativas.

Con estas acciones contribuimos al desarrollo de un tipo de conocimiento no literal del mundo que enriquece la dimensión del conocimiento y lo entiende desde una posición de complejidad, permitiendo una mirada mucho más abierta, plural y diversa, dado que el mundo y todas sus relaciones son extremadamente complicadas. Se fomenta, a través de los procesos creativos, que son a la vez destructivos, y medios visuales, simbólicos y estéticos, una aproximación al mundo alejada de la simplificación. 


\section{Conclusiones}

Se ha constatado que el uso de la c/a/r/tografía en el aula es un instrumento de desarrollo creativo, cognitivo y visual a través de las artes. El método inductivo de estudios de casos y la revisión de la literatura ha dado como resultado la siguiente contribución teórica sobre las c/a/r/tografías.

Características generales. Realizan interrelaciones entre arte, enseñanza e investigación. Son lideradas por investigadores-artistas-docentes dentro de una metodología de investigación a/r/tográfica o por aprendices que desarrollan estos roles. Toman referencias de la cartografía social pedagógica y artística y del mapeo comunitario. Emplea recursos, materiales y técnicas propias del arte contemporáneo. Se generan en entornos educativos físicos o virtuales. El resultado es al mismo tiempo una obra de arte, mapa y representación; un contenido educativo en un momento de enseñanza o taller; una escultura social o evento relacional; una reflexión, una historia, un diálogo y una indagación. Como instrumento de investigación facilita el análisis de datos, la exposición de resultados y la discusión compartida.

Características técnicas. La información se organiza ocupando al máximo la superficie de trabajo. Los datos se organizan sobre una estructura compositiva y simbólica como puede ser un plano (de una ciudad, una escuela), un elemento de la naturaleza (árbol, rizoma...), u otros estereotipos; o bien mediante áreas temáticas que se interconectan (como un tablero de crimen policial). Se parte de una representación vista en planta o alzado dependiendo del esquema empleado para distribuir los datos. El formato y tamaño de trabajo mínimo es proporcional al número de personas que participan del mismo para que tengan cabida a su alrededor trabajando simultáneamente. Se llegan a añadir extensiones o desplegables al formato para ampliar la capacidad de representación. Prevalece el uso de la imagen. El uso del texto 
es complementario a la imagen, integrado con el resto de recursos gráficos. Superan la bidimensionalidad y alcanzan la tridimensionalidad. Los materiales empleados son muy diversos, así como las técnicas: dibujo, pintura, fotografía, maquetas, collage, arte de acción. Se implica el cuerpo, interviniendo la expresión corporal y el movimiento en su elaboración. Se superponen, solapan, entrecruzan o relacionan capas de información y significados. No existe una forma correcta de orientar la representación (un norte) pues a menudo su contenido se distribuye en varias direcciones y sentidos. Pueden aparecer representaciones a diferentes escalas simultáneamente.

Características del proceso creativo. Intervienen metáforas visuales u otras figuras retóricas del lenguaje visual o bien juegos semánticos como elemento fundamental. La simbología y leyendas son fruto de la creatividad, no responden a convenios estandarizados sino de originalidad y conveniencia. Incorporando un lenguaje visual se alfabetiza a quienes la desarrollan. Fomenta la traslación de un pensamiento exclusivamente discursivo y narrativo al de un pensamiento visual, simbólico y estético. Permite indagar en un pensamiento complejo, multidimensional y no lineal. Actúan técnicas de fomento de la creatividad (contagio, rotación, diálogo, inspiración en referentes artísticos). Enfatiza el trabajo colaborativo, aun cuando se trabaja individualmente. No hay un reparto de roles y tareas explícito, sino una autoorganización orgánica de carácter flexible. Se valora siempre el proceso vivo de elaboración, descubrimiento y rectificación fruto de la reflexión compartida, más que una obra final a partir de un boceto previo. Se exponen y exhiben colgadas en paramentos verticales o sobre grandes superficies para ser visualizadas y discutidas de forma grupal. Se hace una crítica estética de la resolución.

En el campo de las a/r/tografías se ha aportado un método concretando sus características generales, características técnicas y características del 
proceso creativo. Se amplían así, las posibilidades que la a/r/tografía ofrece al alumnado y profesorado.

La c/a/r/tografía se ha experimentado en secundaria, en la formación inicial y permanente del profesorado y en centros sociales con sentido pedagógico. Detectada la ausencia de experiencias $\mathrm{c} / \mathrm{a} / \mathrm{r} /$ tográficas en escuelas, esperamos que esta investigación aporte los rasgos definitorios para su implementación en las aulas de infantil, primaria y secundaria. Como prospectiva de futuro nos planteamos investigar la transferencia a estos contextos observando qué adaptaciones didácticas y metodológicas serían precisas. Aunque prevemos dos cuestiones necesarias en la a/r/tografía: el docente tendría una implicación mayor como guía y, el alumnado ejercería el rol docente al asumir el papel de enseñante hacia sus compañeros en lo que se conoce como enseñanza entre iguales en las que unos aprenden de otros, y asumiría también el rol investigador, al tratar de responder a una pregunta de aprendizaje así como el rol artístico en la creación de la c/a/rtografía.

\section{Referencias}

Aberasturi-Apraiz, E., Correa-Gorospe, J. M., y Gutiérrez-Cabello, A. (2020a). Entre lo biográfico y el aprender. Revista Infancia, Educación y Aprendizaje, 6(1), 75-90.

Aberasturi-Apraiz, E., Sasiain, A., Barragán, A. G. C., y Gorospe, J. M. C. (2020b). Cartografiar los espacios de relación: La cartografía y el foto-ensayo como instrumento de indagación colectiva. Tercio creciente, 33-46.

Alonso-Sanz, A. (2020a). Una profesora 'flâneuse' en París. Cartografías en la formación inicial de docentes. Arte, Individuo y Sociedad, 32(2), 363-386. https://dx.doi.org/10.5209/ aris. 63670

Alonso-Sanz, A. (2020b). Mapping of sexist violence in Valencia (Spain). Matter: Journal of New Materialist Research, 1(2), 27-49. 
Baldivieso, M., Di Lorenzo, S., Natalia, L., y Valdez, M. C. (2020). Mapas que conducen a la transformación socio educativa: Experiencias de investigación mediante cartografía social pedagógica y sentidos construidos en relación a la metodología. En T. Fontaines-Ruiz, J. P. Morillo, J. Maza-Cordova, y Y. A. Franco (Coords.), Convergencias y divergencias en investigación (pp. 131-141).

Barbosa, A. M. y Pereira da Cunha, F. (Eds.). (2012). Abordagem Triangular no Ensino das Artes e Culturas Visuais. Cortez.

Barragán, A. G. C., y Aberasturi-Apraiz, E. (2019). Cartografías en torno a los tránsitos en el aprender de docentes en educación infantil y primaria. Educatio Siglo XXI, 37, 93-114.

Barragán-León, A. N. (2019). Cartografía social: lenguaje creativo para la investigación cualitativa. Sociedad y economía, 36, 139-159.

Bassett, K. (2004). Walking as an Aesthetic Practice and a Critical Tool: Some Psychogeographic Experiments. Journal of Geography in Higher Education, 28(3), 397-410. https://doi. org/10.1080/0309826042000286965

Bertling, J. G. (2017). Internship Terrains: Psychogeographically Mapping Place. International Journal of Education Through Art, 13(2), 261-69. 10.1386/eta.13.2.261_1

Bolaños-Motta, J. I. y Pérez-Rodríguez, M. A. (2019). Propuestas para la investigación cualitativa en educación artística. Educación y Educadores 22(1), 51-63. DOI: 10.5294/ edu.2019.22.1.3

Carrasco-Segovia, S., Bogarín, S., y Zúñiga D. (2019). La cartografía artística como ruta de comprensión a las intra-acciones de las experiencias investigativas, pedagógicas y artísticas. Invisibilidades, 12, 48-58.

Carrasco-Segovia, S., y Hernández-Hernández, F. (2020). Cartografiar los afectos y los movimientos en el aprender corporeizado de los docentes. Movimento, 26, 1-14.

Chiesi, L., \& Costa, P. (2015). Making territory through cultural mapping. In J. Atmanagara, J. Dessein, E. Battaglini, y L. Horlings (Eds.), Cultural sustainability and regional development: Theories and practices of territorialisation (pp. 146-161). Routledge.

Crampton, J. W., \& Krygier, J. (2006). An introduction to critical cartography. ACME: an International E-journal for Critical Geographies, 4(1), 11-33.

Dewey, J. (2008). El arte como experiencia. Paidós. 
Efland, A. D. (2004). Arte y cognición. La integración de las artes visuales en el currículum. Octaedro.

Gallego-Lema, V., Gorospe, J. M. C., y Aberasturi-Apráiz, E. (2020). Anywhere, anytime: los itinerarios de aprendizaje de los docentes. Revista Fuentes, 22(2), 165-177.

Giraldo, D. F. B. y Báquiro, J. C. A. (2014). La cartografía social-pedagógica: una oportunidad para producir conocimiento y re-pensar la educación. Itinerario educativo, 28(64), 127 141.

Goodman, N. (1990). Maneras de hacer mundos. Visor.

Goodman, N. (1995). De la mente y otras materias. Visor.

Gorospe, J. M. C., Aberasturi-Apraiz, E., y Belategi, M. (2017). Cartografías sobre cómo aprendemos dentro y fuera de la escuela: lo que nos ha permitido pensar y aprender este proceso de investigación. Revista del IICE, (42), 25-42.

Hernández, F. (2018). Encuentros que afectan y generan saber pedagógico entre docentes a través de cartografías visuales. LAV. Revista Digital do Laboratório de Artes Visuais, 11(2), 103-120.

Hernández, F., Sancho, J. M., \& Domingo, M. (2018). Cartographies as spaces of inquiry to explore of teacher's nomadic learning trajectories. Digital Education Review, 33, 105-119. http://greav.ub.edu/der/

Huerta, R. (2020). El diseño de letras como entorno visual para educar en diversidad. ArtsEduca, 25, 5-22. 10.6035/Artseduca.2020.25.1

Irwin, R. L., \& De Cosson, A. (Eds.). (2004). A/R/Tography: Rendering Self Through Arts-Based Living Inquiry. Pacific Educational Press.

Irwin, R. L., Beer, R., Springgay, S., Grauer, K., Xiong, G., \& Bickel, B. (2006). The Rhizomatic Relations of A/r/tography. Studies in Art Education, 48(1), 70-88.

Irwin, R. L., LeBlanc, N., Yeon Ryu, J., \& Belliveau, G. (2018). A/r/tography as Living Inquiry. In P. Leavy (Ed.), Handbook of Arts-Based Research (pp. 37-53). Guilford Press.

Lasczik, A., \& Irwin, R. L. (2017). Walkings-through paint: A c/a/r/tography of slow scholarship. Journal of Curriculum and Pedagogy, 14(2), 116-124. 10.1080/15505170.2017.1310680

Leavy, P. (Ed.). (2018). Handbook of Arts-Based Research. Guilford Press. 
Lenz, E. (2016). Mapping Invitations to Participate: An Investigation in Museum Interpretation. International Journal of Art \& Design Education, 35(1), 86-106. https://doi.org/10.1111/ jade. 12041

López, W. O. (2013). El estudio de casos: una vertiente para la investigación educativa. Educere, 17(56), 139-144.

Macaya-Ruiz, A. (2017). Trayectos en el mapa: artes visuales como representación del conocimiento. Arte, Individuo y Sociedad, 29(2), 387-404.

Marín-Viadel, R. y Roldán, J. (2019). A/r/tografía e Investigación Educativa Basada en Artes Visuales en el panorama de las metodologías de investigación en Educación Artística. Arte, Individuo y Sociedad, 31(4), 881-895.

McNiff, S. (2013). Art as research: opportunities and challenges. Intellect.

Montenegro, C. (2019). Cartografías colectivas como espacios de reflexión visual: territorios, experiencias y contextos. En IV Congreso Internacional de investigación en artes visuales: ANIAV 2019 (pp. 517-523). Editorial Universitat Politècnica de València.

Morin, E. (2004). Introducción al pensamiento complejo. Gedisa.

Muñiz de la Arena, A. M. y Caeiro, M. (2019). La cognición expresiva como experiencia de relación del arte y la ciencia en la educación preuniversitaria. Artnodes, 24, 142-154. https://doi.org/10.7238/a.v0i24.3259

Pérez, A., \& Libersat, J. U. (2016). ROAM: Walking, Mapping, and Play: Wanderings in Art and Art Education. Studies in Art Education, 57(4), 341-357.

Pinder, D. (1996). Subverting cartography: The situationists and maps of the city. Environment and Planning A, 28(3), 405-427.

Pizarro, E. (2017). Paisajes complejos: hacia una nueva cartografía artística. Revista Europea de Investigación en Arquitectura: REIA, 9, 83-96.

Ramon, R. (2021). The narrative, visual and artistic fiction as a pedagogical research practice of the urban, social and cultural environment. In R. Abeledo (Ed.), Art, culture and economy to democratize society (pp. 119-130). Tirant lo Blanch.

Rees, R. (1980). Historical links between cartography and art. Geographical review, 70(1), 6078. 
Richards, J. C. (2006). Post modern image-based research: An innovative data collection method for illuminating preservice teachers' developing perceptions in field-based courses. The Qualitative Report, 11(1), 37-54.

Rossetto, T. (2015). The Map, the Other and the public visual image. Social \& Cultural Geography, 16(4), 465-491. 10.1080/14649365.2014.998267

Rousell, D., \& Lasczik, A. (2014). Echoes of a C/a/r/tography: Mapping the practicum experiences of pre-service visual arts teachers in the 'visual echoes project'. Australian Art Education, 36(2), 69-82.

Sancho-Gil, J. M., Hernández-Hernández, F., Alonso-Cano, C., Bosco, A., Miño-Puigcercós, R., \& Arrazola-Carballo, J. (2018). Secondary School Teachers' learning geographies and histories. Exploring movements, entanglements and affects. In Nomadic Inquiry. European Congress of Qualitative Inquiry Proceedings (pp. 174-180).

Sinker, R., Giannachi, G., \& Carletti, L. (2013). Art Maps - Mapping the Multiple Meanings of Place. International Journal of Art \& Design Education, 32(3), 362-373. https://doi. org/10.1111/j.1476-8070.2013.12025.x

Springgay, S., Irwin, R. L., Leggo, C., \& Gouzouasis, P. (Eds.). (2008). Being with A/r/tography. Sense Publishers.

Sullivan, G. (2005). Art practice as research: inquiry in the visual arts. Sage Publications.

Yilmaz, E. (2016). Subjectivity in Design Education: The Perception of the City through Personal Maps. International Journal of Art and Design Education, 35(1), 121-139. https://doi. org/10.1111/jade.12005

Cómo citar: Ramon, R. y Alonso-Sanz, A. (2022). La c/a/r/tografía en el aula como instrumento de desarrollo creativo, visual y de pensamiento complejo a través de las artes. Revista KEPES, 19(25), 531-563. https://doi.org/10.17151/kepes.2022.19.25.18 